\title{
Photoinduced Cross-linking Polymerization of Monofunctional Vinyl Monomer without Conventional Photoinitiator and Crosslinker
}

Mehmet Atilla Tasdelen, Volkan Kumbaraci, Naciye Talinli*, Yusuf Yagci*

${ }^{1}$ Istanbul Technical University, Faculty of Science and Letters, Chemistry Department, Maslak, TR-34469, Istanbul, Turkey

*Corresponding authors

E-Mails: tasdelenm@itu.edu.tr, kumbaracii@itu.edu.tr, talinlin@itu.edu.tr, yusuf@itu.edu.tr 


\section{Supporting Information}

\section{Experimental}

\section{Materials}

2-Hydroxyethyl methacrylate (HEMA, 96\%, Acros) and 2-(dimethylamino)ethyl methacrylate (DAEMA, 98\%, Aldrich) were passed through a column of basic alumina before use. Triethylamine (TEA, 98\% J.T. Baker) were dried and distilled over $\mathrm{CaH}_{2}$. Bisbenzodioxinone was synthesized as described previously ${ }^{1}$. Dichloromethane $(99.8 \%$, J.T. Baker) was extracted first with sulfuric acid, then with $5 \% \mathrm{NaOH}$ solutions. After washing with water, the dichloromethane was dried over anhydrous $\mathrm{CaCl}_{2}$ and $\mathrm{CaH}_{2}$ then finally distilled with a fractionation column.

\section{7-hydroxy-2,2-diphenyl-4H-benzo[d][1,3]dioxin-4-one $(1)^{2}$}<smiles>O=C(O)c1ccc(O)cc1O</smiles>

Trifluoroacetic acid $(12$ mL) a round bottom flask containing 2,4- dihydroxybenzoic acid (2.5 g, $16.2 \mathrm{mmol}, 1 \mathrm{eq})$ and benzophenone $(4.4 \mathrm{~g}, 24.4 \mathrm{mmol}, 1.5 \mathrm{eq})$ at $0^{\circ} \mathrm{C}$, under $\mathrm{N}_{2}$. The reaction was warmed to $\mathrm{rt}$ and then stirred for $24 \mathrm{~h}$. The slightly yellow homogeneous mixture was concentrated and the residue was dissolved in toluene $(40 \mathrm{~mL})$ and concentrated again. This operation was repeated 3 times. The crude residue was purified by column chromatography. (silicagel, $30 \%$ EtOAc/Hexanes) to yield $0.9 \mathrm{~g}(17 \%)$. m.p.:63-65 ${ }^{\circ} \mathrm{C}$.

${ }^{1} \mathrm{H}-\mathrm{NMR}\left(\mathrm{CDCl}_{3}\right): \delta=10.43(\mathrm{~s}, 1 \mathrm{H}, \mathrm{OH}), 7.60-7.54(\mathrm{dd}, J=7.4, J=1.4,4 \mathrm{H}, \mathrm{Ar}), 7.35-7.31$ (m, $6 \mathrm{H}, \mathrm{Ar}), 7.71(\mathrm{~d}, J=8.7,1 \mathrm{H}, \mathrm{Ar}), 6.63(\mathrm{~s}, 1 \mathrm{H}, \mathrm{Ar}), 6.52$ (d, J=8.6, 1H, Ar).

FT-IR: $3230,2975,1687,1612,1594,1491,1447,1240,1121,960,750 \mathrm{~cm}^{-1}$

$\mathrm{UV}\left(\mathrm{CH}_{2} \mathrm{Cl}_{2}\right)$ : $\lambda_{\max .}, \mathrm{nm}\left(\varepsilon, 1 \mathrm{~mol}^{-1} \mathrm{~cm}^{-1}\right) ; 303$ (8932), 263(18470), 229 (21869).

\section{7-(2-bromoethoxy)-2,2-diphenyl-4H-benzo[d][1,3]dioxin-4-one;}

A solution of benzodioxinone (1) $(0.7 \mathrm{~g}, 2.2 \mathrm{mmol})$ and anhydrous potassium carbonate $(5 \mathrm{~g}$, $36.2 \mathrm{mmol})$ in acetone $(25 \mathrm{~mL})$ were stirred for three hours. After that time, 1,2-dibromoethane $(0.6 \mathrm{~mL}, 6.6 \mathrm{mmol})$ was added and the mixture was heated at reflux temperature for 16 hours. The reaction was diluted with ether $(100 \mathrm{~mL})$, filtered through a pad of celite, and concentrated 
on the rotary evaporator. After the volume was reduced to app. $50 \%$, remaining solution was purified by column chromatography (over silicagel $30 \%$ EtOAc-Hexane) and afforded the desired bromoethoxy benzodioxinone (2). Then, 7-(2-bromoethoxy)-benzodioksinon (2) recrystallized from carbon tetrachloride to yield $0.2 \mathrm{~g}(21 \%)$. m.p.:143-145 ${ }^{\circ} \mathrm{C}$.

${ }^{1} \mathrm{H}-\mathrm{NMR}\left(\mathrm{CDCl}_{3}\right): \delta=7.76(\mathrm{~d}, J=8.7,1 \mathrm{H}, \mathrm{Ar}), 7.59$-7.56 (m, 4H, $\left.\mathrm{Ar}\right), 7.36-7.31(\mathrm{~m}, 6 \mathrm{H}, \mathrm{Ar})$, $6.62(\mathrm{~s}, 1 \mathrm{H}, \mathrm{Ar}), 6.57(\mathrm{~d}, J=8.6,1 \mathrm{H}, \mathrm{Ar}), 4.31\left(\mathrm{t}, J=6.2,2 \mathrm{H}, \mathrm{CH}_{2} \mathrm{O}\right), 3.63\left(\mathrm{t}, J=6.1,2 \mathrm{H}, \mathrm{CH}_{2} \mathrm{Br}\right.$ ) .

FT-IR: $3059,2920,1723,1615,1581,1444,1263,1165,959,760 \mathrm{~cm}^{-1}$

$\mathrm{UV}\left(\mathrm{CH}_{2} \mathrm{Cl}_{2}\right)$ : $\lambda_{\max }, \mathrm{nm}\left(\varepsilon, 1 \mathrm{~mol}^{-1} \mathrm{~cm}^{-1}\right) ; 296$ (5110), 263(13122), 229 (20055).

\section{Model study ${ }^{3}$}

Typical procedure: A solution of 7-(2-bromoethoxy)-benzodioxinone (35 mM) and P(HEMAco-MMA) which synthesized as described previously ${ }^{1}(33 \mathrm{~g} / \mathrm{L})$ in dichloromethane were put in pyrex tube and filled with dry nitrogen prior to irradiation from Rayonet merry-go-round photoreactor equipped with 16 lamps emitting nominally at $\lambda>300 \mathrm{~nm}$ with a light intensity of $3 \times 10^{-3} \mathrm{~mW} \mathrm{~cm}^{-2}$. The light insensity was measured by Delta ohm HD-9021 power meter. At the end of given time, modified copolymers were recovered by precipitation of the irradiated solutions into 10-fold excess hexane and dried in vacuum.

\section{Real-Time Infrared Spectroscopy Photopolymerization Studies:}

Typical procedure: A solution of bisbenzodioxinone $(5 \mathrm{mM})$, 2-hydroxyethyl methacrylate (HEMA, $4000 \mathrm{mM}$ ) and triethyl amine (TEA $15 \mathrm{mM}$ ) or 2-dimethylamino ethyl methacrylate (DAEMA, $15 \mathrm{mM}$ ) in $1 \mathrm{~mL}$ dichloromethane were put in $\mathrm{NaCl}$ window with dry nitrogen.

The samples were placed in the compartment of a Fourier transform infrared spectrometer (Perkin Elmer FT-IR Spectrum One B) and were simultaneously exposed to a UV photolyzing light and an IR analyzing light beam. The photolyzing light was generated by a Rayonet merrygo-round photoreactor equipped with 16 lamps emitting nominally at $\lambda>300 \mathrm{~nm}$ with a light intensity of $3 \times 10^{-3} \mathrm{~mW} \mathrm{~cm}^{-2}$ as measured by Delta ohm HD-9021 power meter. At the end of the given time, cross-linked polymers were recovered by removing solvent under reduced pressure. 


\section{Characterizations}

${ }^{1} \mathrm{H}-\mathrm{NMR}$ spectra of 5-10\% (w/w) solutions in $\mathrm{CDCl}_{3}$ with $\mathrm{Si}\left(\mathrm{CH}_{3}\right)_{4}$ as an internal standard were recorded at room temperature at 250, respectively, on a Bruker DPX 250 spectrometer. FT-IR spectra were recorded on a Perkin-Elmer FT-IR Spectrum One B spectrometer. UV spectra were recorded on a Shimadzu UV-1601 spectrometer.

\section{References and Notes}

1. V. Kumbaraci, N. Talinli and Y. Yagci, Macromol Rapid Commun. 2007, 28, 72-77

2. J.Garcia-Fortanet, J. R. Debergh, and J. K. De Brabander Org Lett. 2005, 7, 685-688

3. ${ }^{1} \mathrm{H}-\mathrm{NMR}$ spectral analysis of the photoirradiated polymer revealed that $43 \mathrm{~mol} \%$ of the hyrdroxyl groups were reacted as calculated from the ratio of integration of the $\mathrm{a}+\mathrm{f}$ and $\mathrm{g}$ protons to c and d protons (see Figure 1). 

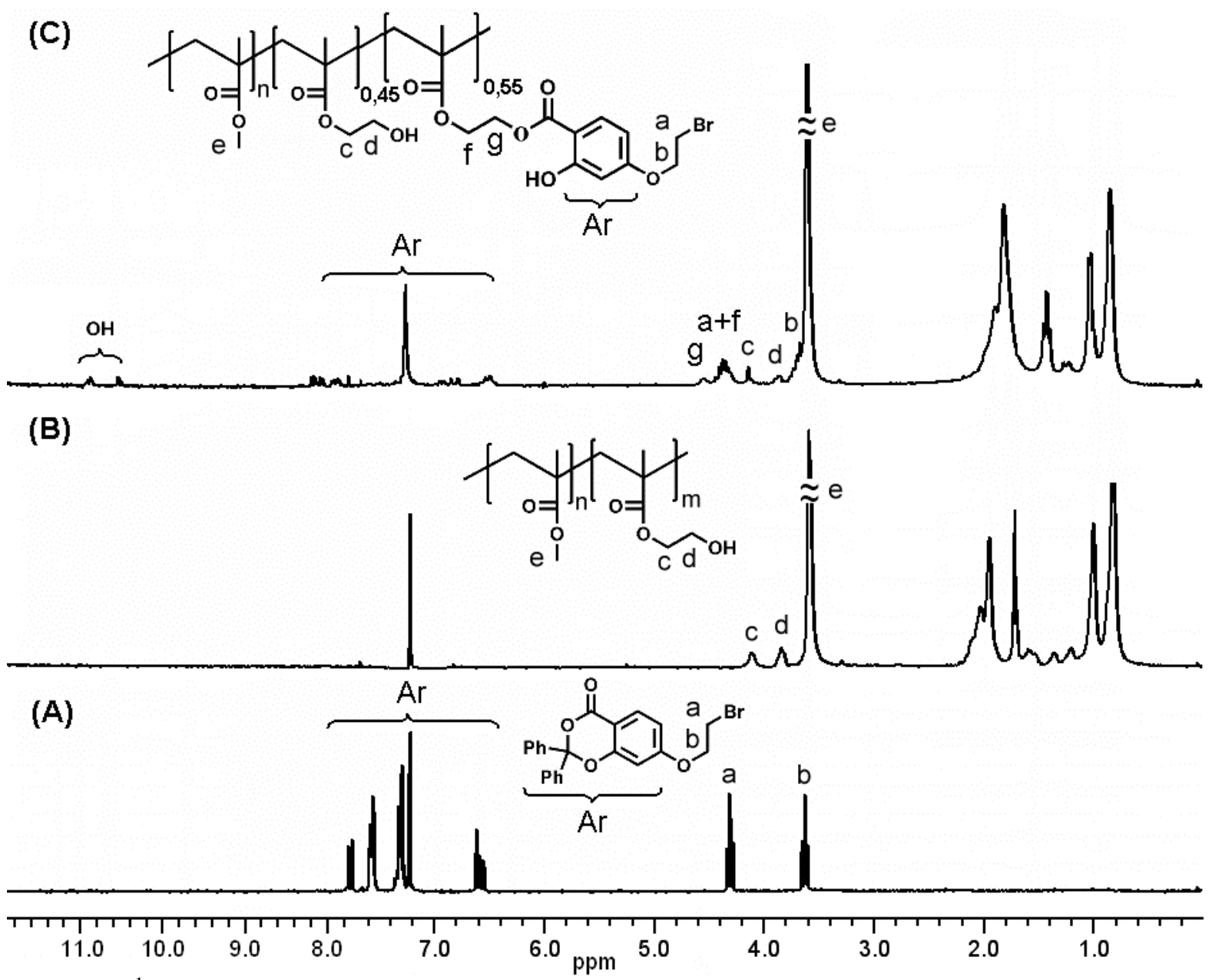

Figure 1. ${ }^{1} \mathrm{H}-\mathrm{NMR}$ spectra of 7-(2-bromoethoxy) benzodioxinone (A), P(HEMA-co-MMA) (B) and their photolysis product (C). 


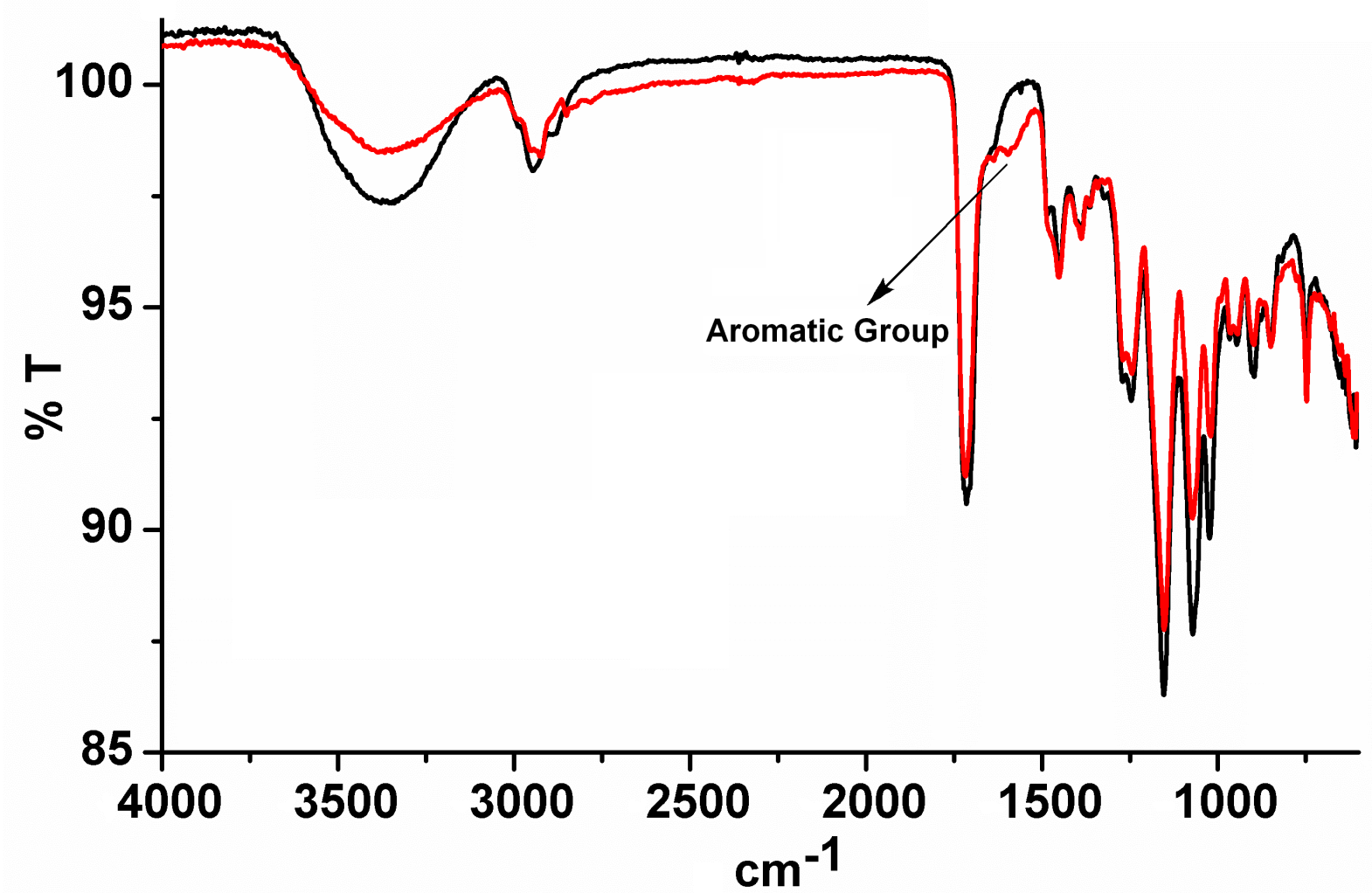

Figure 2. FT-IR spectra of homo PHEMA (black) and crosslinked product of photolysis of HEMA and bisbenzodioxinone (red). 